\section{Rooting Characteristics of Buffalograsses Grown in Flexible Plastic Tubes}

\author{
Kenneth B. Marcum ${ }^{1}$, M.C. Engelke, and Sharon J. Morton \\ Texas A\&M University Research Center, Dallas, TX 75252
}

Additional index words. Buchloë dactyloides, root length, root count, root weight, grass breeding

\begin{abstract}
Rooting characteristics of 22 buffalograss [Buchlö̈ dactyloides (Nutt.) Engelm.] genotypes were determined by growing plants in clear, sand-filled polyethylene tubes in a glasshouse. Differences were observed among entries for average maximum root depth, total root weight, root count and weight at increasing $100-\mathrm{mm}$ depth increments, and total shoot weight. Average maximum root depth was positively correlated with total root weight $(r=0.59)$ and with root count at each $100-\mathrm{mm}$ root profile depth. Root count and weight across all vertical root profile sections were highly correlated $(r=0.81)$. Total shoot weight was weakly correlated with average maximum root depth but not at all with total root weight. Grasses with superior rooting characteristics (deeply rooted, with larger root mass and count in the lower root profile sections) included AZ-143, NTDG-1, and ' 315 ' (NE84-315).
\end{abstract}

Development and use of drought-resistant turfgrasses are of primary interest to those in the turfgrass industry, as water availability for irrigating landscapes is becoming increasingly limited. Improved understanding of turfgrass drought-resistance mechanisms would improve turfgrass management strategies and speed the development of drought-resistant cultivars. Deep rooting and extensive root branching, particularly at lower root profile depths (Kramer, 1983), are considered important root system characteristics favoring plant water uptake and survival under dry soil conditions (Russell, 1977). Deep rooting is considered a drought-resistance mechanism in numerous plants (Levitt, 1980).

Deep rooting and large root volumes have been associated with drought resistance under dry soil conditions in wheat (Triticumaestivum L.) (Narayan, 1991) and rice (Oryza sativa L.) (Zuno-Altoveros et al., 1990). In turfgrass, differences in rooting characteristics have been noted among cultivars of Kentucky bluegrass (Poa pratensis L.) (Ensign and Weiser, 1975) and creeping bentgrass (Agrostis palustris Huds.) (Lehman and Engelke, 1991; Salaiz et al., 1991). Differences in vertical root distribution among 10 bermudagrass [Cynodon dactylon (L.) Pers.] cultivars were associated with maintenance of turf quality under drought stress in a greenhouse (Hays et al., 1991). Root depth, root count at lower root profile depths,

Received for publication 2 Feb. 1995. Accepted for publication 5 July 1995 . Reference to a trade name is for specific information only and does not imply endorsement of the product. The cost of publishing this paper was defrayed in part by the payment of page charges. Under postal regulations, this paper therefore must be hereby marked advertisement solely to indicate this fact.

${ }^{1}$ Current address: Dept. of Plant Sciences, Univ. of Arizona, Tucson, AZ 85721. and total root weights of 11 zoysiagrasses (Zoysia spp.) grown in flexible plastic tubes in a glasshouse were positively correlated with field drought resistance (Marcum et al., 1995).

Buffalograss, which is native to the semiarid North American "short grass" prairie (Turgeon, 1991), is often used for landscaping in low-rainfall areas and is considered to have good to excellent drought tolerance (Emmons, 1995; Kim, 1987). However, to our knowledge, little is known concerning the rooting characteristics of buffalograsses. The objective of these experiments was to determine if glasshouse.

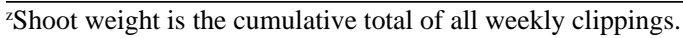

differences exist in the genetic potential for rooting of a broad range of buffalograss genotypes grown under nonlimiting conditions in a glasshouse.

\section{Materials and Methods}

Twenty-two buffalograss entries (see Table 1) were initially seeded or planted vegetatively into plug trays containing sterilized growing medium (25\% Canadian sphagnum peat, $55 \%$ no. 3 grade horticultural vermiculite, and $20 \%$ horticultural perlite). Seeded entries were 'Sharps Improved', 'Bison', 'Top Gun', 'Plains', and all NTDG entries. Grasses were maintained by clipping weekly at $50 \mathrm{~mm}$ and fertilizing weekly at a rate of $\approx 3.1 \mathrm{~kg} \mathrm{~N} / \mathrm{ha}$ from a fertilizer solution $(20 \mathrm{~N}-8.7 \mathrm{P}-16.6 \mathrm{~K})$ until densely established.

Plugs ( $25 \mathrm{~mm}$ in diameter) of the 22 entries were transplanted into sand-filled polyethylene tubes $[25 \mathrm{~mm}$ in diameter $\times 900 \mathrm{~mm}$ long (0.076-mm wall thickness)] (Chiswick, Sudbury, Mass.) on 18 Sept. 1991. The tubes were filled with a fine silica sand of uniform particle-size distribution ( $96 \%$ between 0.15 to $1.0 \mathrm{~mm}$ in diameter) and had been uniformly mixed with a $14 \mathrm{~N}-6.7 \mathrm{P}-16.6 \mathrm{~K}$ resincoated fertilizer (Osmocote) to provide an $\mathrm{N}$ level of $5 \mathrm{~g} \cdot \mathrm{m}^{-2}$. Before the plugs were planted, the tubes were inserted into PVC pipe (43-mm inside diameter) and suspended in racks tilted $30^{\circ}$ from vertical (Lehman and Engelke, 1991).

Tubes were placed in a glasshouse ranging from 16 to $26 \mathrm{C}$ during the study. Natural daylight was supplemented by high-pressure sodium vapor lights at $400 \mu \mathrm{mol} \cdot \mathrm{m}^{-2} \cdot \mathrm{s}^{-1}$ for 12 $\mathrm{h}$ daily. The sand medium was maintained at field capacity by mist irrigation three times daily. Tubes were arranged in a randomized

Table 1. Average maximum root depth (AMRD = average of three deepest roots), total root fresh weight, and shoot dry weight of 22 buffalograss entries grown on a sand medium in flexible plastic tubes in a

\begin{tabular}{lccc}
\hline \hline Entry & $\begin{array}{c}\text { AMRD } \\
(\mathrm{mm})\end{array}$ & $\begin{array}{c}\text { Total root } \\
\text { wt (mg) }\end{array}$ & $\begin{array}{c}\text { Shoot wt } \\
(\mathrm{mg})^{\mathrm{z}}\end{array}$ \\
\hline Cultivar & & & 461 \\
Bison & 350 & 646 & 366 \\
Buffalawn & 360 & 519 & 401 \\
Plains & 346 & 589 & 330 \\
Prairie & 295 & 605 & 370 \\
Sharps Improved & 294 & 357 & 485 \\
Texoka & 276 & 572 & 337 \\
Top Gun & 320 & 453 & 397 \\
315 & 384 & 846 & 401 \\
378 & 372 & 815 & 449 \\
609 & 353 & 640 & 425 \\
Experimental line & & & 406 \\
AZ-143 & 413 & 904 & 419 \\
Highlight 4 & 363 & 632 & 457 \\
Highlight 15 & 285 & 381 & 401 \\
Highlight 25 & 375 & 606 & 271 \\
NE84-436 & 306 & 591 & 355 \\
NE84-45-3 & 261 & 392 & 322 \\
NTDG-1 & 433 & 740 & 301 \\
NTDG-2 & 313 & 429 & 304 \\
NTDG-3 & 328 & 620 & 322 \\
NTDG-4 & 377 & 643 & 443 \\
NTDG-5 & 337 & 726 & 110 \\
Rutgers & 379 & 467 & 299 \\
LSD & 76 & & \\
\hline Sh & & &
\end{tabular}

y Means separated using Fisher's protected LSD procedure at $P \leq 0.05$. 
complete-block design with six replications.

Maximum root depth was monitored weekly by marking on the bottom side of the polyethylene tube face. Roots of all entries within a replication were taken for analysis when roots of one entry in that replication reached the bottom of the polyethylene tube. The six replications were harvested for analysis over 4 weeks, the final replication being taken on 25 Jan. 1992. Shoots were clipped weekly at $50 \mathrm{~mm}$ throughout the experiments, dried at 70C, and pooled for total shoot clipping dry weights.

At root harvest, the three longest roots (three maximum root depths) were marked on each polyethylene tube face and recorded. Rooting depth is reported as average maximum root depth $(\mathrm{AMRD}=$ total length of three longest roots/3). Each tube was then slit with a razor, leaving the intact sand column laying horizontally on a wire-mesh trough. Sand was gently washed away, leaving the root profile in its original configuration on the screen. The root profile was cut into $100-\mathrm{mm}$ sections from the sand-plug interface $(0 \mathrm{~mm})$, each root section tied together with thread immediately below the cut, placed in weak $(\approx 3$ g.liter ${ }^{-1}$ ) thymol solution (preservative), and refrigerated until analysis.

Root counts per 100-mm depth were determined by counting the number of severed roots at each $100-\mathrm{mm}$ root section interface with a stereo microscope. Each 100-mm root section was then thoroughly blotted dry and weighed to determine root weight distribution with depth. Total root fresh weight is the sum of the weights of each root section.

A second, identical experiment was initiated 28 Mar. 1992. The six replications were taken over 3 weeks, the final replication taken on 15 Aug. 1992. No significant experiment $\times$ treatment interaction was found by analysis of variance (ANOVA), and Pearson product moment correlation between the two experiments was highly significant, so data are reported as an average of two experiments. Data were analyzed by ANOVA procedure (SAS Institute, 1985), and entry means separated using Fisher's protected LSD. Treatment means were correlated using Pearson product moment correlation.

\section{Results and Discussion}

Average maximum root depth ranged from $433 \mathrm{~mm}$ for NTDG-1 to 261 for NE84-45-3 (Table 1). Grasses within the top $20 \%$ for AMRD, in decreasing order, were NTDG-1, AZ-143, '315', Rutgers, NTDG-4, Highlight 25, '378' (NE85-378), Highlight 4, 'Buffalawn', '609' (NE84-609), 'Bison', and 'Plains'.

Root count was correlated with AMRD at each depth, the best correlation being at middle depths, 200 to $400 \mathrm{~mm}$ (Table 2). Grasses with the most roots at the lower root profile depth of $400 \mathrm{~mm}$, in decreasing order, were AZ-143, Highlight 25, '609', NTDG-1, NTDG-5, '315', Highlight 4, and NTDG-4 (Table 3). Of these, only AZ-143 and NTDG-1 had an average of one or more roots at $500 \mathrm{~mm}$.
Total root weight ranged from $904 \mathrm{mg}$ for AZ-143 to $357 \mathrm{mg}$ for 'Sharps Improved' (Table 1). Grasses within the top 20\% for total root weight, in decreasing order, were AZ143, '315', '378', NTDG-1, and NTDG-5. Total root weight was highly correlated with AMRD, and with root count at 0 - through 400$\mathrm{mm}$ depths (Table 2). Total root weight was significantly, though less strongly, correlated with root count at the $500-\mathrm{mm}$ depth.

Root weights per $100-\mathrm{mm}$ vertical root profile section differed significantly at all depths (Table 4). Grasses with highest root weights at the lower root profile depth of 400 to $500 \mathrm{~mm}$, in decreasing order, were NTDG-1, AZ-143, NTDG-5, NTDG-4, Highlight 25, '609', and Rutgers. Root counts and weights across all vertical root profile sections were correlated $(R=0.81)$.

Cumulative shoot dry weights ranged from $486 \mathrm{mg}$ for 'Texoka' to $272 \mathrm{mg}$ for NE84-45-3 (Table 1). Shoot dry weight was correlated with AMRD, but not with total root weight. In contrast, shoot dry weight was correlated with rooting depth and total root weight in zoysiagrass (Marcum et al., 1995). In that study, both rooting characteristics, but not shoot dry weight, were good predictors of drought resistance. Shoot dry weight also was correlated with root counts at 0 - through 400$\mathrm{mm}$ depths, but not at the 500-mm depth, the strongest correlations being at depths of 0 to $200 \mathrm{~mm}$. The association of shoot dry weight and root count at shallow depths may be related to shoot count. 'Texoka' had the highest shoot dry weight, but low AMRD and total root weight. However, root counts were high at shallow depths of 0 and $100 \mathrm{~mm}$.

Deeply rooted grasses (having large AMRD values) generally also had high total root weights, and many roots and high root weights in lower root profile sections ( 300 to $500 \mathrm{~mm}$ ). The best-performing grasses overall, having the largest values noted, were AZ-143, NTDG-1, and ' 315 '. Rutgers and Highlight 25 had large AMRD and root counts at lower root profile depths, but low total root weights.

Assessing root growth via flexible plastic tubes in a glasshouse is an efficient method for screening many plant materials for several reasons. The technique 1) is less expensive than field coring or excavation techniques; 2 )

Table 2. Correlation coefficients $(r)$ for average maximum root depth (AMRD), total root weight, root counts at increasing 100-mm depths, and cumulative shoot clipping dry weight of buffalograsses grown in a sand medium under glasshouse conditions.

\begin{tabular}{|c|c|c|c|c|c|c|c|c|}
\hline \multirow{2}{*}{$\begin{array}{l}\text { Root } \\
\text { characteristic } \\
\text { and depth }(\mathrm{mm})\end{array}$} & \multirow{2}{*}{$\begin{array}{l}\text { Total } \\
\text { root } \\
\text { wt }\end{array}$} & \multicolumn{6}{|c|}{ Root counts/depth (mm) } & \multirow{2}{*}{$\begin{array}{c}\text { Shoot } \\
\text { wt }\end{array}$} \\
\hline & & 0 & 100 & 200 & 300 & 400 & 500 & \\
\hline AMRD & $0.59^{* * *}$ & $0.20^{* * *}$ & $0.30^{* * * *}$ & $0.58^{* * *}$ & $0.65^{* * *}$ & $0.53^{* * * *}$ & $0.39^{* * * *}$ & $0.28^{* * *}$ \\
\hline Weight & & $0.43^{\text {**** }}$ & $0.53^{* * *}$ & $0.70^{\text {**** }}$ & $0.69^{* * *}$ & $0.47^{* * * *}$ & $0.18^{* *}$ & 0.11 \\
\hline Count at 0 & & & $0.56^{* * * *}$ & $0.30^{* * * *}$ & $0.23^{* *}$ & $0.14^{*}$ & 0.08 & $0.37^{* * * *}$ \\
\hline 100 & & & & $0.52^{* * * *}$ & $0.32^{* * *}$ & $0.22^{* *}$ & 0.03 & $0.39^{* * *}$ \\
\hline 200 & & & & & $0.71^{* * * *}$ & $0.42^{* * *}$ & $0.16^{* *}$ & $0.31^{* * *}$ \\
\hline 300 & & & & & & $0.60^{* * * *}$ & $0.24^{* *}$ & $0.17^{* *}$ \\
\hline 400 & & & & & & & $0.36^{* * *}$ & $0.14^{*}$ \\
\hline 500 & & & & & & & & -0.03 \\
\hline
\end{tabular}

***,*** Correlation coefficients significantly different from 0 at $P \leq 0.05,0.01$, or 0.0001 , respectively.

Table 3. Root counts at successive 100-mm vertical profile depths of 22 buffalograss entries grown on a sand medium in flexible plastic tubes in a glasshouse.

\begin{tabular}{|c|c|c|c|c|c|c|}
\hline \multirow[b]{2}{*}{ Entry } & \multicolumn{6}{|c|}{ Root counts at each $100-\mathrm{mm}$ root section } \\
\hline & 0 & 100 & 200 & 300 & 400 & 500 \\
\hline \multicolumn{7}{|l|}{ Cultivar } \\
\hline Bison & 21.3 & 14.4 & 12.8 & 6.4 & 1.4 & 0.0 \\
\hline Buffalawn & 29.7 & 19.5 & 19.4 & 11.1 & 1.4 & 0.6 \\
\hline Plains & 20.3 & 16.6 & 14.3 & 7.4 & 1.4 & 0.1 \\
\hline Prairie & 29.6 & 32.3 & 11.0 & 3.1 & 0.0 & 0.0 \\
\hline Sharps Improved & 18.6 & 14.0 & 7.9 & 2.4 & 0.2 & 0.0 \\
\hline Texoka & 35.3 & 22.0 & 10.0 & 3.1 & 0.1 & 0.0 \\
\hline Top Gun & 22.9 & 15.3 & 10.5 & 4.8 & 0.9 & 0.0 \\
\hline 315 & 40.1 & 24.0 & 15.5 & 12.9 & 3.7 & 0.0 \\
\hline 378 & 26.6 & 20.4 & 16.8 & 7.5 & 2.4 & 0.0 \\
\hline 609 & 22.7 & 19.8 & 15.7 & 10.4 & 4.4 & 0.0 \\
\hline \multicolumn{7}{|l|}{ Experimental line } \\
\hline AZ-143 & 29.0 & 20.9 & 19.1 & 17.3 & 7.4 & 1.1 \\
\hline Highlight 4 & 17.7 & 16.9 & 12.9 & 9.7 & 3.7 & 0.2 \\
\hline Highlight 15 & 19.1 & 17.4 & 9.2 & 8.4 & 2.7 & 0.0 \\
\hline Highlight 25 & 17.4 & 11.9 & 14.1 & 10.2 & 4.9 & 0.0 \\
\hline NE84-436 & 26.2 & 18.0 & 10.9 & 3.5 & 1.1 & 0.0 \\
\hline NE84-45-3 & 27.2 & 14.6 & 4.6 & 2.5 & 1.5 & 0.0 \\
\hline NTDG-1 & 19.8 & 17.2 & 17.7 & 9.4 & 4.4 & 1.0 \\
\hline NTDG-2 & 22.1 & 12.4 & 11.1 & 3.9 & 1.0 & 0.1 \\
\hline NTDG-3 & 22.7 & 14.7 & 9.9 & 8.2 & 1.8 & 0.0 \\
\hline NTDG-4 & 20.9 & 16.5 & 10.6 & 6.5 & 3.5 & 0.2 \\
\hline NTDG-5 & 28.6 & 19.3 & 11.5 & 7.1 & 3.9 & 0.2 \\
\hline Rutgers & 23.5 & 21.4 & 14.4 & 7.0 & 2.2 & 0.7 \\
\hline $\mathrm{LSD}_{0.05}{ }^{\mathrm{z}}$ & 8.4 & 8.0 & 7.9 & 7.2 & 4.6 & 0.7 \\
\hline
\end{tabular}

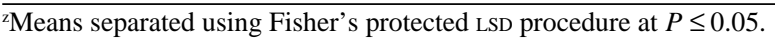


Table 4. Root fresh weight of successive 100-mm vertical root profile sections of 22 buffalograss entries grown on a sand medium in flexible plastic tubes in a glasshouse.

\begin{tabular}{|c|c|c|c|c|c|c|}
\hline \multirow[b]{2}{*}{ Entry } & \multicolumn{6}{|c|}{ Root wt (mg)/vertical section (mm) } \\
\hline & $0-100$ & $100-200$ & $200-300$ & $300-400$ & $400-500$ & $500-600$ \\
\hline \multicolumn{7}{|l|}{ Cultivar } \\
\hline Bison & 283 & 196 & 115 & 46 & 6 & 0 \\
\hline Buffalawn & 217 & 135 & 105 & 50 & 11 & 1 \\
\hline Plains & 267 & 164 & 103 & 45 & 10 & 1 \\
\hline Prairie & 349 & 190 & 54 & 11 & 0 & 0 \\
\hline Sharps Improved & 194 & 107 & 44 & 10 & 2 & 0 \\
\hline Texoka & 374 & 132 & 52 & 13 & 0 & 0 \\
\hline Top Gun & 218 & 146 & 66 & 18 & 5 & 0 \\
\hline 315 & 390 & 211 & 146 & 86 & 13 & 0 \\
\hline 378 & 384 & 210 & 158 & 56 & 6 & 0 \\
\hline 609 & 257 & 171 & 141 & 56 & 15 & 0 \\
\hline \multicolumn{7}{|l|}{ Experimental line } \\
\hline AZ-143 & 319 & 237 & 177 & 135 & 34 & 2 \\
\hline Highlight 4 & 236 & 170 & 127 & 88 & 10 & 0 \\
\hline Highlight 15 & 169 & 106 & 64 & 35 & 7 & 0 \\
\hline Highlight 25 & 222 & 156 & 138 & 72 & 17 & 0 \\
\hline NE84-436 & 333 & 163 & 73 & 21 & 1 & 0 \\
\hline NE84-45-3 & 254 & 93 & 28 & 13 & 4 & 0 \\
\hline NTDG-1 & 251 & 218 & 149 & 85 & 34 & 3 \\
\hline NTDG-2 & 216 & 116 & 75 & 18 & 4 & 0 \\
\hline NTDG-3 & 293 & 161 & 104 & 54 & 8 & 0 \\
\hline NTDG-4 & 313 & 141 & 117 & 53 & 19 & 0 \\
\hline NTDG-5 & 350 & 181 & 107 & 65 & 19 & 1 \\
\hline Rutgers & 176 & 138 & 102 & 36 & 14 & 2 \\
\hline $\operatorname{LSD}_{0.05}{ }^{\mathrm{z}}$ & 131 & 90 & 74 & 52 & 21 & 2 \\
\hline
\end{tabular}

${ }^{2}$ Means separated using Fisher's protected LSD procedure at $P \leq 0.05$.

reduces variability due to localized changes in field soil temperature, texture, and water content; and 3) allows nondestructive monitoring of root extension through time.

Differences in root depth, total root weight, and root weights and counts at increasing root profile depths (root distribution) were found among 22 buffalograss genotypes grown in flexible plastic tubes. Deep rooting under water-limiting conditions in the field was associated with drought resistance in corn (Zea mays L.) (Lorens et al., 1987) and wheat (Narayan, 1991), while total root volume was associated with drought resistance in rice
(Zuno-Altoveros et al., 1990). Differences in root mass distribution with depth, but not shoot dry weight, were associated with bermudagrass quality (relative percentage of green leaves) in a greenhouse experiment where irrigation depth was gradually lowered through time (Hays et al., 1991). Rooting characteristics of creeping bentgrasses grown in flexible plastic tubes in a glasshouse were heritable (Lehman and Engelke, 1991), suggesting that this technique might be used as a screening procedure in selecting turfgrasses having the superior rooting characteristics necessary for improved drought resistance.

\section{Literature Cited}

Emmons, R.D. 1995. Turfgrass science and management. 2nd ed. Delmar Publishers, New York.

Ensign, R.D. and G.C. Weiser. 1975. Root and rhizome development of some Kentucky bluegrass and red fescue cultivars. Agron. J. 67:583585.

Hays, K.L., J.F. Barber, M.P. Kenna, and T.G. McCollum. 1991. Drought avoidance mechanisms of selected bermudagrass genotypes. HortScience 26:180-182.

Kim, K.S. 1987. Comparative drought resistance mechanisms of eleven major warm-season turfgrasses. PhD Diss., Texas A\&M Univ., College Station.

Kramer, P.J. 1983. Water relations of plants. Academic, New York.

Lehman, V.G. and M.C. Engelke. 1991. Heritability estimates of creeping bentgrass root systems grown in flexible tubes. Crop Sci. 31:16801684.

Levitt, J. 1980. Responses of plants to environmental stresses. vol. I. Chilling, freezing, and high temperature stresses. Academic, New York.

Marcum, K.B., M.C. Engelke, S.J. Morton, and R.H. White. 1995. Rooting characteristics and associated drought resistance of zoysiagrasses. Agron. J. 87(3):534-537.

Narayan, D. 1991. Root growth and productivity of wheat cultivars under different soil moisture conditions. Intl. J. Ecol. \& Environ. Sci. 17(1):19-26.

Russell, R.S. 1977. Plant root systems: Their function and interaction with the soil. McGraw-Hill, U.K.

Salaiz, T.A., R.C. Shearman, T.P. Riordan, and E.J. Kinbacher. 1991. Creeping bentgrass cultivar water use and rooting responses. Crop Sci. 31:1331-1334.

SAS Institute. 1985. SAS procedures guide for personal computers, version 6 ed. SAS Inst., Cary, N.C.

Turgeon, A.J. 1991. Turfgrass management. 3rd ed. Prentice Hall, Englewood Cliffs, N.J.

Zuno-Altoveros, C., G.C. Loresto, M. Obein, and T.T.Chang. 1990. Differences in root volume of selected upland and lowland rice varieties. Intl. Rice Res. Nwsl. 15(2):8. 